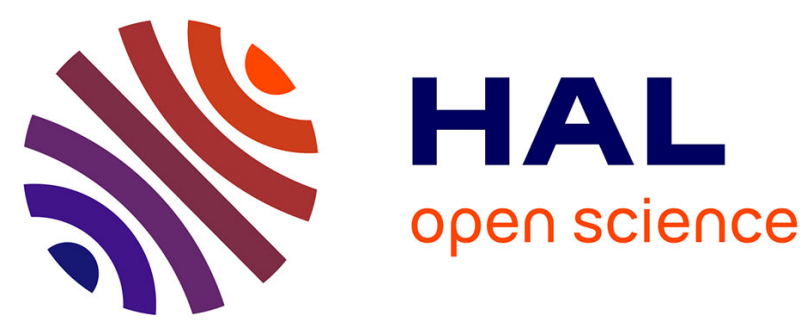

\title{
Actionable molecular alterations in advanced gynaecologic malignancies: updated results from the ProfiLER programme
}

Romain Varnier, Olivia Le Saux, Sylvie Chabaud, Gwenaëlle Garin, Emilie Sohier, Qing Wang, Sandrine Paindavoine, David Pérol, Christian Baudet, Valéry Attignon, et al.

\section{To cite this version:}

Romain Varnier, Olivia Le Saux, Sylvie Chabaud, Gwenaëlle Garin, Emilie Sohier, et al.. Actionable molecular alterations in advanced gynaecologic malignancies: updated results from the ProfiLER programme. European Journal of Cancer, 2019, 118, pp.156 - 165. 10.1016/j.ejca.2019.06.017 . hal03487380

\author{
HAL Id: hal-03487380 \\ https://hal.science/hal-03487380
}

Submitted on 21 Dec 2021

HAL is a multi-disciplinary open access archive for the deposit and dissemination of scientific research documents, whether they are published or not. The documents may come from teaching and research institutions in France or abroad, or from public or private research centers.
L'archive ouverte pluridisciplinaire HAL, est destinée au dépôt et à la diffusion de documents scientifiques de niveau recherche, publiés ou non, émanant des établissements d'enseignement et de recherche français ou étrangers, des laboratoires publics ou privés.

\section{(ㄷ)(1) $\$$}

Distributed under a Creative Commons Attribution - NonCommerciall 4.0 International 
2 Title: Actionable molecular alterations in advanced gynecologic malignancies: updated results from

3 the ProfiLER program

4 Authors:

5

1. Romain Varnier ${ }^{1,2}$

6

2. Olivia Le Saux ${ }^{3}$

7

3. Sylvie Chabaud ${ }^{4}$

4. Gwenaëlle Garin ${ }^{4}$

9

5. Emilie Sohier ${ }^{5,6}$

10

6. $\quad$ Qing Wang ${ }^{5}$

7. Sandrine Paindavoine ${ }^{6}$

8. David Pérol ${ }^{4}$

9. Christian Baudet ${ }^{5,6}$

10. Valéry Attignon ${ }^{5}$

11. Daniel Pissaloux $x^{2,7}$

12. Pierre Heudel ${ }^{3}$

13. Benoit You ${ }^{2,8}$

14. Cécile Leyronnas ${ }^{9}$

15. Olivier Collard ${ }^{10}$

16. Olivier Trédan ${ }^{3}$ 


\section{Affiliations list:}

${ }^{1}$ Medical Practices Evaluation team - HESPER EA7425, Centre Léon Bérard, Lyon, France

${ }^{2}$ Université Claude Bernard Lyon 1, Lyon, France

${ }^{3}$ Department of Medical Oncology, Centre Léon Bérard, Lyon, France

${ }^{4}$ Department of Clinical Research, Centre Léon Bérard, Lyon, France

${ }^{5}$ Department of Translational Research, Centre Léon Bérard, Lyon, France

${ }^{6}$ Synergie Lyon Cancer, Plateforme de bioinformatique 'Gilles Thomas', Centre Léon Bérard, Lyon, France

${ }^{7}$ Department of Biopathology, Centre Léon Bérard, Lyon, France

${ }^{8}$ CITOHL, IC-HCL, Hospices Civils de Lyon, Université Claude Bernard Lyon 1, Lyon, France

${ }^{9}$ Department of Medical Oncology, Institut Daniel Hollard, Grenoble, France

${ }^{10}$ Department of Medical Oncology, Institut Lucien Neuwirth, Saint-Priest-En-Jarez, France

${ }^{11}$ Department of Medical Oncology, Hôpital Privé Jean Mermoz, Lyon, France

${ }^{12}$ INRIA Grenoble Rhône-Alpes, Montbonnot Saint-Martin, France

Corresponding author: Prof Isabelle Ray-Coquard. Department of Medical Oncology, Centre Léon isabelle.ray-coquard@lyon.unicancer.fr

Key words: precision medicine; gynecologic cancer; molecular targeted agents; next generation sequencing; aCGH. 
Abstract:

Objectives: The objectives of this study were to identify actionable genomic alterations in the gynecological subpopulation of the ProfiLER program and to report clinical efficacy of recommended targeted therapies (RTT).

Methods: The ProfiLER program (NCT01774409) is a multicentric prospective trial aiming to implement molecular profiling in patients with advanced refractory cancers. In this program, tumor DNA is analyzed by targeted next-generation sequencing (69 genes) and by whole genome array comparative genomic hybridization. Clinical cases and genomic profiles are presented in a dedicated molecular tumor board to guide treatment strategies. We report here an analysis of patients with gynecological cancers included in this trial.

Results: From February 2013 to February 2017, 309 gynecologic cancer patients were included; 279 (90\%) had sufficient quality and 131 patients $(42.4 \%)$ had at least one actionable genomic alteration in cancer cells. Four alterations were shared by at least 3\% of the patients: 27 (9.7\%) PIK3CA mutations, 15 (5.4\%) KRAS mutations, 11 (3.9\%) ERBB2 amplifications and 9 (3.2\%) CDKN2A deletions. Fortyone treatments were initiated among 39 patients (12.6\% of the screened population): 8 (20\%) had a partial response and other $10(24 \%)$ had a stable disease. Median progression-free survival was 2.7 months. Median overall survival was 15.6 months for patients who received a RTT.

Conclusion: Molecular profiling identified actionable alterations in $42.4 \%$ of patients with advanced refractory gynecologic cancer but only $12.6 \%$ were treated with a RTT. Among them, $46 \%$ derived clinical benefit (5.8\% of the screened population). 
Gynecologic malignancies affect more than 1 million women each year and cause the death of 494000 of them worldwide (1). First-line strategy for patients with ovarian, endometrial and cervical cancer is based on tumor histopathology (2-4). Recently, better knowledge of carcinogenesis and progress in molecular biology has led to the development of targeted treatments such as tyrosine-kinase inhibitors or monoclonal antibodies (5). Today, in gynecologic cancers, only bevacizumab and PARP inhibitors are approved for ovarian cancer in different settings (6-10) and bevacizumab for metastatic cervical cancer in first-line (11).

Precision medicine tests the hypothesis that genomic characterization of tumors provides genomic biomarkers that may guide decisions of treatment with targeted oncogene treatment (12). Gynecologic cancers are heterogeneous and genomic analysis of these tumors has already been interrogated by The Cancer Genomic Atlas (TCGA) (13-15). Feasibility and interest of precision medicine programs have been reported (16-24), but clinical data are still lacking in gynecologic oncology. ProfiLER is a French multicentric clinical trial (NCT01774409) aiming to identify "actionable alterations" in patients with advanced solid tumors (25). The main objective of this study was to analyze the results of this program in patients with advanced refractory gynecologic malignancies. 


\section{Patients and methods}

90

\section{Study design}

The ProfiLER program is a non-randomized, prospective, multicentric cohort study, combined with a biological sample collection and a clinical data collection, dedicated to cancer patients after standard of care. The study was approved by the French National Agency for Medication Security (ANSM) and by a national ethics committee (CPP Sud-Est IV). This study is registered in ClinicalTrials.gov, number NCT01774409.

\section{Inclusion criteria}

Patients were aged over 18 and available tumor (fresh or archival) sample was required. After written consent, a blood sampling was done and archival tumor samples (from initial diagnosis or relapse) were used. Patients were recruited during their medical care, either during standard management or in the case of therapeutic failure.

This study includes the subpopulation of female patients with locally advanced, relapsed or metastatic gynecologic malignancies of all histology types. Rare gynecologic tumors (defined as non-high-grade ovarian carcinomas, non-endometrioid endometrial carcinomas, non-squamous cervical carcinomas and other primary tumors) could also be recruited, with a specific focus. Indeed, the promoting center is the French national reference center for rare gynecological tumors (TMRO network).

\section{Tumor sample management}

After central quality control by a pathologist, each tumor sample underwent molecular analyses in the promoting center. Sixty-one genes and 8 hot-spot regions of cancer-related genes (Supplementary table 1) were sequenced by targeted Next Generation Sequencing (Ion Torrent PGM Sequencer, Life Technologies) to assess mutations, insertions and deletions. Copy number variations of whole genome were studied by array Comparative Genomic Hybridization (Agilent platform or Affymetrix platform). The minimal DNA input amount needed was of 200ng for NGS and $1.5 \mu \mathrm{g}$ for aCGH. 
114 A dedicated panel of clinicians and scientists reviewed tumor genomic profiles in order to determine

115 the relevance of identified genomic alterations and recommended targeted treatment, matching one (or 116 more) actionable alterations when it was clinically relevant. This molecular board was held on a 117 weekly basis. Recommended targeted treatment (RTT) had to be approved by national authorities or 118 available through a clinical trial. Results and conclusions of this meeting were reported in the medical 119 record of the patient and sent to the investigator.

\section{Endpoints}

121 The main objective was to describe actionable molecular alterations in the gynecologic cancer patients of the ProfiLER program. Secondary objectives were to evaluate access to recommended targeted treatments and identify limitations to their implementation, and to assess efficacy of RTT in this setting.

\section{Assessments}

Characteristics of patients and disease history since diagnosis were retrospectively collected after inclusion. All data were updated until July 31, 2017.

Patients with a treatment recommendation were followed according to the study protocol if included in a clinical trial, or according to the routine practice for off-label use. Response to RTT was evaluated according to RECIST 1.1 (26) using best response rates. Clinical benefit rate (CBR) was defined as the percentage of patients achieving either a complete response (CR), or a partial response (PR) or stable disease (SD).

\section{Statistical analysis}

134 As inclusion in the study could occur throughout the course of the disease, overall survival (OS) was defined as time from the molecular tumor board until death (any cause) or latest news. OS was estimated using the Kaplan-Meier method and survival curves were generated. The reverse Kaplan-

137 Meier method was used to estimate the median follow-up durations. All analyses were performed 138 using SAS version 9.4. 
141 From February 2013 to February 2017, out of the first 2579 patients included in the ProfiLER

142 program, 309 had advanced gynecologic cancers (12\%) (Figure 1). Thirty patients (9.7\%) were excluded due to insufficient quality or quantity of tumor material and 279 tumor samples with a median cellularity of $70 \%$ were available: $188(67.4 \%)$ were primary tumors, while $72(25.8 \%)$ were metastatic samples and 10 (3.6\%) were relapsed tumor samples (missing data for 9 samples). Finally, 279 patients $(90.3 \%)$ were presented to the molecular board with at least one genomic analysis: NGS analysis for 263 patients (94.3\%), aCGH for 248 patients (88.8\%) and both for 234 (83.9\%) patients. Median time between inclusion in the ProfiLER program and decision by the molecular board was 2.9 months (range from 0.4 to 10.6).

Patient's characteristics are reported in Table 1. Ovarian malignant tumors were the most frequent cancers $(n=176,63 \%)$, followed by uterine tumors $(n=61,22 \%)$, cervical tumors $(n=32,11 \%)$ and other localizations $(n=10,4 \%)$. Altogether, $118(42.3 \%)$ patients had a rare histological form gynecologic cancer. Detailed histological subtypes are described in Table 2.

Genomic alterations

Among 309 screened patients, 131 patients (42.4\% of the screened population and $47 \%$ of the patients with molecular analysis) had at least one actionable genomic alteration, including 48 patients (15.5\%) who presented several actionable alterations (Table 3). The actionable alteration rate was similar for patients with rare tumors ( $n=56,47.5 \%$ of analyzed patients). Overall, 209 actionable genomic alterations were reported (Figure 2 and Supplementary Table 2).

160 Genomic alterations were mainly missense mutations (at least one identified in 77 patients; $28 \%$ of 161 patients with molecular analysis) and gene amplifications ( $n=57 ; 20 \%)$. Twenty-two (8\%) 162 homozygous deletions were also identified. Four genomic alterations were shared by at least $3 \%$ of the patients: 27 (9.7\%) PIK3CA hot-spot mutations, 15 (5.4\%) KRAS hot-spot mutations, 11 (3.9\%) ERBB2 amplifications and 9 (3.2\%) CDKN2A (P16/INK4) homozygous deletions (Figure 2). Genes 
encoding for proteins in the PI3K-AKT-mTOR pathway, RAS-RAF-MEK-ERK pathway, cell cycle and $E R B B$ family were frequently altered, with 52 (18.6\%), 31 (11.1\%), 25 (9.0\%) and $14(5 \%)$ patients respectively.

\section{Recommended treatments and access to recommended targeted treatments}

A targeted treatment was recommended for 99 patients (32\%). Median number of previous lines of chemotherapy was 3 (range from 1 to 9). The most frequently recommended treatments were everolimus (n=32), sorafenib (n=26), PI3K-AKT/mTOR inhibitors $(n=19)$ and anti-HER2 targeted therapy $(n=9)$ (Table 3). With a median follow-up of 17.9 months since the molecular tumor board decision, 39 out of 99 patients with a recommended therapy (39\%, 12.6\% of the screened population) initiated a RTT (Figure 1 and Supplementary Table 3). Sixty patients (19.4\%) could not get access to a recommended targeted treatment despite actionable alterations: 17 patients (5.5\%) had impaired general status (PS > 2), 12 patients $(3.9 \%)$ had no progressive disease at the time of the analysis, 11 (3.6\%) were proposed for other treatment , 7 died (2.3\%), 5 (1.6\%) of them had no access to adequate clinical trial, $5(1.6 \%)$ were lost to follow-up and 2 patients $(0.6 \%)$ had a contraindication. Two patients began two lines of treatment by RTT. Four RTT were prescribed "off-label" and the 37 others were administered within specific clinical trials, such as the "MOST Plus" (NCT02029001) baskettrial promoted by the Centre Leon Bérard.

\section{Efficacy of recommended targeted treatments}

Forty-one RTT lines were initiated among 39 patients. Two patients died, and one patient stopped the clinical trial due to toxicity before any tumor evaluation. Among the 38 evaluable treatment lines, 8 patients (20\%) had a partial response to everolimus (n=3), LY2780301, pazopanib, sorafenib, trastuzumab and vemurafenib, and $10(24 \%)$ had a stable disease. Clinical benefit rate was $5.8 \%$ (18/309) for the entire screened population. Twenty patients (49\%) had progressive disease at the time of the first evaluation. Median PFS was 2.7 months (95\% CI 2.3-4.7) for patients receiving RTT (Figure 3A). 
190 Forty patients died before the molecular board and were not included in the overall survival analysis.

191 Median OS was 15.6 months $(95 \% \mathrm{CI}=6.6-33)$ for the 39 patients who initiated a RTT and 14.2 192 months $(95 \% \mathrm{CI}=11-17.4)$ for the 200 patients who did not receive RTT $(p=0.44)$ (Figure $3 B)$. The 193 OS of patients with at least one actionable alteration was not significantly different to that of patients 194 with no detectable molecular alteration with the ProfiLER panel (Figure 3C). 
197 The objective of this study was to describe the landscape of actionable genomic alterations in tumors in the gynecologic subpopulation of the ProfiLER program, and their impact on patient outcome. At the time of the analysis, $90 \%$ of the eligible patients had an aCGH and/or a targeted NGS performed on their tumor sample, within a median time of 2.9 months after inclusion. Therefore, analysis of somatic genomic alterations was shown to be feasible in routine practice.

Actionable genomic alterations were identified in $42.4 \%$ of patients with advanced refractory gynecologic malignancies, a proportion which is similar to that of other tumor sites already reported in the global population of the ProfiLER program (25). This result is also consistent with Takenaka et al. (16) findings on 72 ovarian cancers (49\%), with Spreafico et al. (17) study about 55 ovarian cancers (64\%) and with Muller et al. (18) results about 29 cervical tumors (59\%). Freixinos et al. (19) and Rodriguez et al. (20) identified a greater number of actionable alterations (respectively $72 \%$ and 93\%) in gynecologic cancers patients using a bigger gene panel (more than 250 genes compared to only 69). Whether larger panels can provide a larger proportion of patients with actionable alteration is being explored currently including in the PROFILER-02 randomized clinical trial (NCT03163732).

In the present study, identification of an alteration led to a treatment recommendation in 99 patients (32\%). At the time of interim analysis of the NCI-MATCH trial, about one in five gynecologic cancer

213 patients tested (23\%) had a gene abnormality that paired with a study drug (22). Comparisons must be

214 done cautiously due to the lack of common criteria to define 'actionable' alterations. The ESMO Scale 215 for Clinical Actionability of molecular Targets (ESCAT) (27) should avoid this issue for future 216 studies.

217 Rare histological subtypes of gynecologic tumors were over-represented (42.4\%) in our study. 218 Actionability rate was $47.5 \%$ for them, leading to treatment recommendations to 41 patients (34.7\%) 219 contrasting with the usual lack of therapeutic possibilities for these patients. 
indeed the most frequent altered genes in respectively $11.5 \%, 7.5 \%$ and $4.7 \%$ of the 279 patients with genomic analyses presented to the molecular board.

BRCA1/2 mutations were identified specifically in the panel in only $2.8 \%$ of ovarian cancers patients, compared to $22 \%$ in the TCGA program (13). This results from a selection bias towards rare histologic subtypes of the present series. Also high-grade ovarian serous adenocarcinomas already benefited from systematic $B R C A$ testing in clinical practice (29) and previously identified $B R C A$ mutations were not re-explored.

Only 39 of our 99 patients (39.3\%) with a RTT actually initiated the treatment which represents $12.6 \%$ of the screened population. As already described (30), access to RTT was limited by the lack of open trials evaluating these drugs, but also by impaired general status of our patients. However the present access rate was relatively high compared to the global population of the ProfiLER program (163/699: 23\%) (25) and to similar studies (19\% in Freixinos et al. (19), $43 \%$ in Spreafico et al. (17) and 36\% in Rodriguez et al. (20)).

This trial was not designed to evaluate clinical efficacy. Nevertheless, clinical benefit rate (CBR) to RTT in advanced refractory gynecologic cancer was interesting with 18 partial responses or stable disease out of 41 RTT lines initiated (44\%). Yet only 5.8\% of the whole screened population benefited from RTT. In another setting, in metastatic breast cancer patients, the SAFIR01 study reported a CBR of $30 \%(23)$.

Responses to RTT were variable and the range of PFS was wide (from 1.5 to 18.3 months, the longest for a patient treated with everolimus for a squamous cell carcinoma of the cervix). The survival of patients treated with RTT was not significantly different to that of the other patients: of course, this analysis is considerably biased and cannot serve to establish the value of the strategy used in this research program. Randomized trials comparing RTT vs conventional care will need to be implemented. Pairwise comparison with the results of the previous and following treatment lines may also be informative (31). Several patients with PIK3CA mutations showed promising responses to LY2780301 and everolimus, needing to be confirmed. 
The limited response rate results from different phenomenons: 1) the absence of efficient models to predict for the biological role of a given molecular alteration in a given patient, 2) from the clonal heterogeneity of metastatic cancers, 3) the limited sequencing panel 4) the lack of availability of appropriate RTT, 5) the significant drop-off of patients from MTB to initiation of RTT.

In $67 \%$ of the patients, molecular analyses were performed on tumor samples from initial surgery of the primary tumor. In the future, liquid biopsy may help overcome this problem (32). The present screening strategy enables to reduce the empirical approach used in the past to select second or latter line treatments in many cancers. Still, it will be important to develop tools to better characterize key molecular cancer drivers in given patients for the development of precision oncology (33).

To our knowledge, this study is one of the largest programs of precision medicine in gynecologic oncology reported so far. There are however limitations to this study. Patients included in the ProfiLER program were selected late and heavily pre-treated. Molecular analyses were performed using technologies which have largely improved (while being less costly) since the initiation of this program. Similarly, interpretation by the molecular board may have evolved with science knowledge and experience of the participants during the four years.

\section{Conclusion}

This study helped to better characterize the genomic profile of gynecologic malignancies. Nearly half of the patients had actionable molecular alterations, using a small gene panel testing (less than 100 genes), but one third of patients actually received the recommended RTT. Future trials will have to explore broader gene panels and ensure that a larger proportion of patients have access to the recommended treatment in order to determine more precisely the value of this strategy. General genomic screening of cancers cells to guide the treatment of advanced gynecological cancer patients refractory to standard treatment remains a topic of research, to be evaluated in future clinical trials.

271 Proposal of such molecular analysis for metastatic patients needs to be anticipated and not to be reserved for patients after several lines of systemic treatments. 
Dr. Tredan reports personal fees from Roche, personal fees from Novartis, personal fees from Lilly, personal fees from Astra-Zeneca, personal fees from Pfizer, during the conduct of the study. Dr. Pérol reports personal fees from Roche, personal fees from Lilly, personal fees from Astra-Zeneca, during

277 the conduct of the study. Dr. Blay reports grants from Roche, grants from Novartis, grants from Bayer,

278 grants from GSK, during the conduct of the study. All other authors have nothing to disclose.

279

\section{Author contribution}

SC, GG, DPe, OT, PC, JYB and IRC designed the study. ES, CB and AV realized bioinformatics analyzes. QW, SP, VA and DPi performed molecular analyzes. PH, BY, CL, OC, OT, NB, JL, JPJ, PC, OD, GF, JYB and IRC recruited and followed-up patients. RV and OLS collected data. SC realized statistical analysis. RV, OLS, SC and IRC interpreted data. RV and OLS wrote the manuscript draft. IRC reviewed the manuscript. All authors read and accepted the final version of the manuscript.

\section{Acknowledgments}

- Work funded by LYric (DGOS-INCa-4664).

- Aid granted by Bpifrance Financement abounded by European Community (E8983 PREDICTIV).

- The authors thank Leila Ben Abdesselem, Véronique Corset and Magali Myard who helped conducting this study, and the Clinical Research Associates of each center. 
1. Siegel RL, Miller KD, Jemal A. Cancer statistics, 2018. CA Cancer J Clin. 2018 Jan;68(1):7-30.

2. Marth C, Landoni F, Mahner S, McCormack M, Gonzalez-Martin A, Colombo N. Cervical cancer: ESMO Clinical Practice Guidelines for diagnosis, treatment and followup. Ann Oncol. 2017 Jul 1;28(suppl_4):iv72-83.

3. Colombo N, Creutzberg C, Amant F, Bosse T, González-Martín A, Ledermann J, et al. ESMO-ESGO-ESTRO Consensus Conference on Endometrial Cancer: diagnosis, treatment and follow-up. Ann Oncol. 2016 Jan 1;27(1):16-41.

4. Ledermann JA, Raja FA, Fotopoulou C, Gonzalez-Martin A, Colombo N, Sessa C. Newly diagnosed and relapsed epithelial ovarian carcinoma: ESMO Clinical Practice Guidelines for diagnosis, treatment and follow-up. Ann Oncol. 2013 Oct 1;24(suppl_6):vi24-32.

5. Hanahan D, Weinberg RA. Hallmarks of Cancer: The Next Generation. Cell. 2011 Mar 4;144(5):646-74.

6. Burger RA, Brady MF, Bookman MA, Fleming GF, Monk BJ, Huang H, et al. Incorporation of bevacizumab in the primary treatment of ovarian cancer. N Engl J Med. 2011 Dec 29;365(26):2473-83.

7. Ledermann J, Harter P, Gourley C, Friedlander M, Vergote I, Rustin G, et al. Olaparib 
a preplanned retrospective analysis of outcomes by BRCA status in a randomised phase 2 trial. The Lancet Oncology. 2014 Jul 1;15(8):852-61.

8. Mirza MR, Monk BJ, Herrstedt J, Oza AM, Mahner S, Redondo A, et al. Niraparib Maintenance Therapy in Platinum-Sensitive, Recurrent Ovarian Cancer. N Engl J Med. 2016 01;375(22):2154-64.

9. Oza AM, Cook AD, Pfisterer J, Embleton A, Ledermann JA, Pujade-Lauraine E, et al.

11. Tewari KS, Sill MW, Long HJ, Penson RT, Huang H, Ramondetta LM, et al. Improved survival with bevacizumab in advanced cervical cancer. N Engl J Med. 2014 Feb 20;370(8):734-43.

12. Coyne GO, Takebe N, Chen AP. Defining precision: The precision medicine initiative trials NCI-MPACT and NCI-MATCH. Curr Probl Cancer. 2017 Jun;41(3):182-93.

13. Network TCGAR. Integrated genomic analyses of ovarian carcinoma. Nature. 2011 Jun;474(7353):609-15.

14. Levine DA, The Cancer Genome Atlas Research. Integrated genomic characterization of endometrial carcinoma. Nature. 2013 May;497(7447):67-73. 
15. Ojesina AI, Lichtenstein L, Freeman SS, Pedamallu CS, Imaz-Rosshandler I, Pugh TJ, et al. Landscape of Genomic Alterations in Cervical Carcinomas. Nature. 2014 Feb 20;506(7488):371-5.

16. Takenaka M, Saito M, Iwakawa R, Yanaihara N, Saito M, Kato M, et al. Profiling of actionable gene alterations in ovarian cancer by targeted deep sequencing. International Journal of Oncology. 2015 Jun 1;46(6):2389-98.

17. Spreafico A, Oza AM, Clarke BA, Mackay HJ, Shaw P, Butler M, et al. Genotypematched treatment for patients with advanced type I epithelial ovarian cancer (EOC). Gynecol Oncol. 2017 Feb;144(2):250-5.

18. Muller E, Brault B, Holmes A, Legros A, Jeannot E, Campitelli M, et al. Genetic profiles of cervical tumors by high-throughput sequencing for personalized medical care. Cancer Med. 2015 Oct 1;4(10):1484-93.

19. Freixinos VR, Lheureux S, Mandilaras V, Clarke B, Dhani N, Mackay H, et al. Integration of somatic molecular profiling for rare epithelial gynaecologic cancer patients. J Clin Oncol [Internet]. 2016 [cited 2017 Mar 15];34(suppl; abstr 5509). Available from: http://meetinglibrary.asco.org/content/169764-176

20. Rodriguez-Rodriguez L, Hirshfield KM, Rojas V, DiPaola RS, Gibbon D, Hellmann M, et al. Use of comprehensive genomic profiling to direct point-of-care management of patients with gynecologic cancers. Gynecologic Oncology. 2016 Apr;141(1):2-9.

21. Gunderson CC, Rowland MR, Wright DL, Andrade KL, Mannel RS, McMeekin DS, et al. Initiation of a formalized precision medicine program in gynecologic oncology. Gynecologic Oncology. 2016 Apr;141(1):24-8. 
22. Barroilhet L, Matulonis U. The NCI-MATCH trial and precision medicine in gynecologic cancers. Gynecologic Oncology. 2018 Mar 1;148(3):585-90.

23. André F, Bachelot T, Commo F, Campone M, Arnedos M, Dieras V, et al. Comparative genomic hybridisation array and DNA sequencing to direct treatment of metastatic breast cancer: a multicentre, prospective trial (SAFIR01/UNICANCER). The Lancet Oncology. 2014 Mar;15(3):267-74.

24. Le Tourneau C, Delord J-P, Gonçalves A, Gavoille C, Dubot C, Isambert N, et al. Molecularly targeted therapy based on tumour molecular profiling versus conventional therapy for advanced cancer (SHIVA): a multicentre, open-label, proof-of-concept, randomised, controlled phase 2 trial. The Lancet Oncology. 2015 Oct;16(13):1324-34.

25. Trédan O, Wang Q, Pissaloux D, Cassier P, de la Fouchardière A, Fayette J, et al. Molecular screening program to select molecular-based recommended therapies for metastatic cancer patients: analysis from the ProfiLER trial. Ann Oncol. 2019; 30: doi:10.1093/annonc/mdz080.26. Eisenhauer EA, Therasse P, Bogaerts J, Schwartz LH, Sargent D, Ford R, et al. New response evaluation criteria in solid tumours: revised RECIST guideline (version 1.1). Eur J Cancer. 2009 Jan;45(2):228-47.

27. Mateo J, Chakravarty D, Dienstmann R, Jezdic S, Gonzalez-Perez A, Lopez-Bigas N, et al. A framework to rank genomic alterations as targets for cancer precision medicine: the ESMO Scale for Clinical Actionability of molecular Targets (ESCAT). Ann Oncol. 2018 Sep 1;29(9):1895-902.

28. Kim MK, Caplen N, Chakka S, Hernandez L, House C, Pongas G, et al. Identification of therapeutic targets applicable to clinical strategies in ovarian cancer. BMC Cancer 
[Internet]. 2016 Aug 24 [cited 2017 Jan 25];16(1). Available from: http://www.ncbi.nlm.nih.gov/pmc/articles/PMC4997769/

29. Gladieff L, Lyonnet DS, Lortholary A, Leary A, Genestie C, Ray-Coquard I. Cancers de l'ovaire BRCA muté : consultation d'oncogénétique et prescription des inhibiteurs de PARP. Bulletin du Cancer. 2017 May 1;104:S16-23.

30. Hillman RT, Ward K, Saenz C, McHale M, Plaxe S. Barriers Prevent Patient Access to Personalized Therapies Identified by Molecular Tumor Profiling of Gynecologic Malignancies. J Pers Med. 2015 May 21;5(2):165-73.

31. Massard C, Michiels S, Ferté C, Deley M-CL, Lacroix L, Hollebecque A, et al. HighThroughput Genomics and Clinical Outcome in Hard-to-Treat Advanced Cancers: Results of the MOSCATO 01 Trial. Cancer Discov [Internet]. 2017 Apr 1 [cited 2019 Feb 20]; Available from: http://cancerdiscovery.aacrjournals.org/content/early/2017/03/26/2159-8290.CD-161396

32. Yi X, Ma J, Guan Y, Chen R, Yang L, Xia X. The Feasibility of Using Mutation Detection in ctDNA to Assess Tumor Dynamics. Int J Cancer. 2017 Jan 1;n/a-n/a.

33. Bailey MH, Tokheim C, Porta-Pardo E, Sengupta S, Bertrand D, Weerasinghe A, et al. Comprehensive Characterization of Cancer Driver Genes and Mutations. Cell. 2018 Apr 5;173(2):371-385.e18. 
Table and figures legends

$401 \quad$ Supplementary table 1: sequenced genes

$402 *$ Only hot-spot mutation regions were sequenced for these 8 genes

403 Figure 1: Flow chart

404 Table 1: Patients characteristics

405 Table 2: Localization and histology of tumors

406 Table 3: Conclusions of the molecular tumor board

407 Figure 2: Actionable genomic alterations

408 Supplementary Table 2: Classification of the actionable genomic alterations by type of tumor

409 (percentages; background color from red to green by decreasing frequency)

410 Figure 3: A) Progression free survival of patients receiving a recommended targeted treatment B)

411 Overall survival of patients receiving a recommended targeted treatment and of patients treated with

412 conventional systemic treatment in the gynecologic population C) Overall survival of patients with 413 actionable alteration(s) and patients without any actionable alteration

414 Supplementary Table 3: initiated RTT

415 PD: progressive disease, SD: stable disease, PR: partial response, NA: not available 


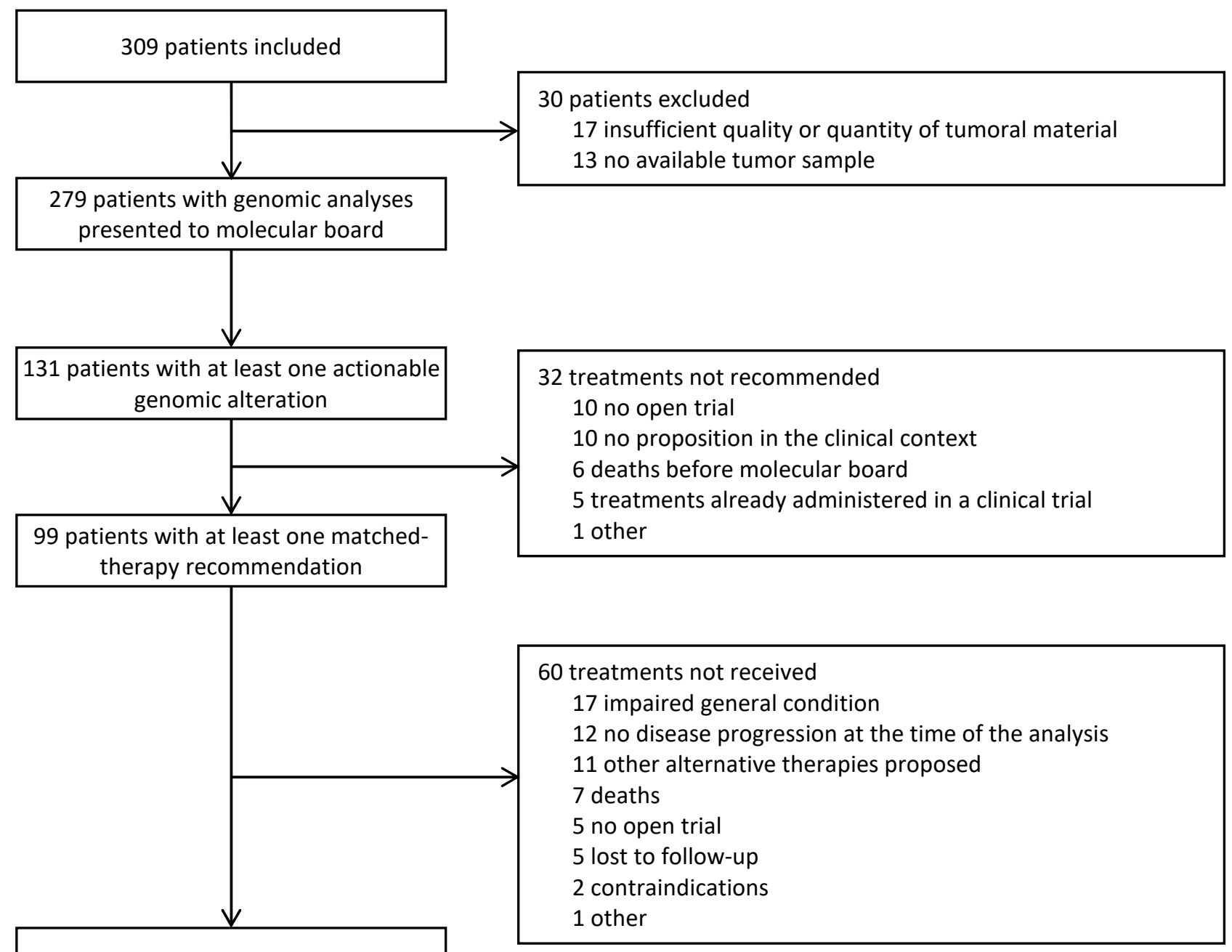

39 patients received matched therapy 


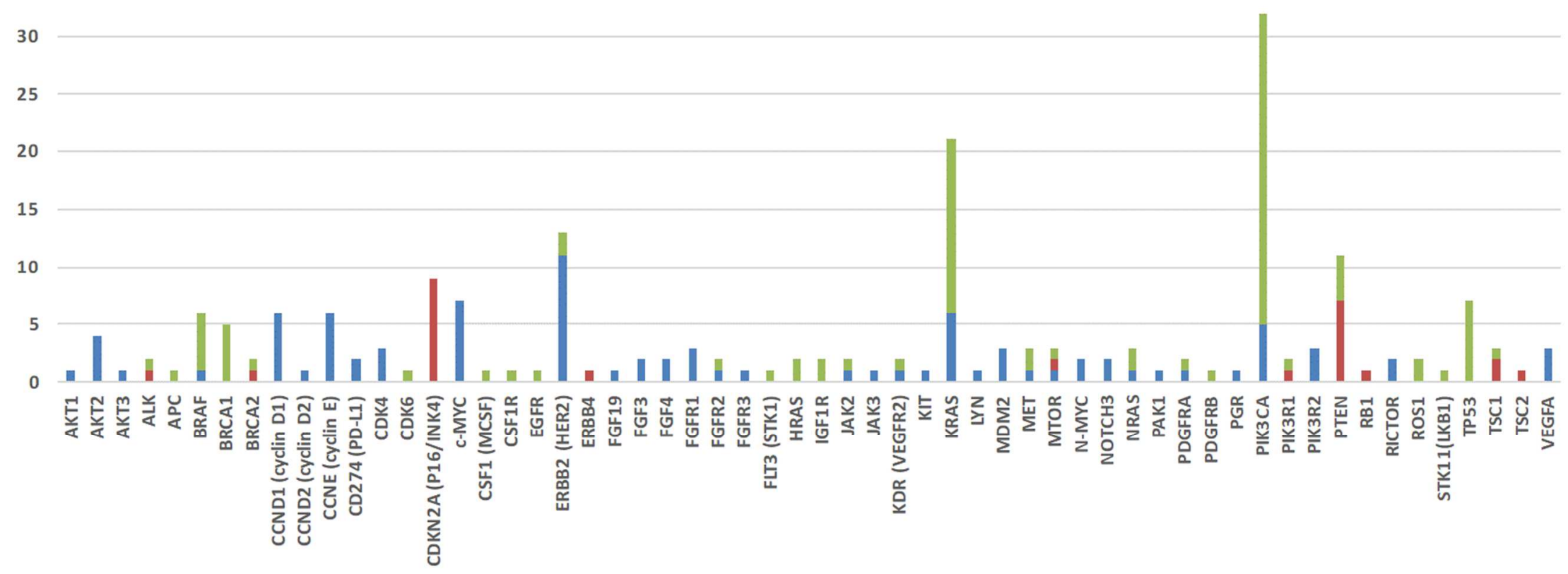

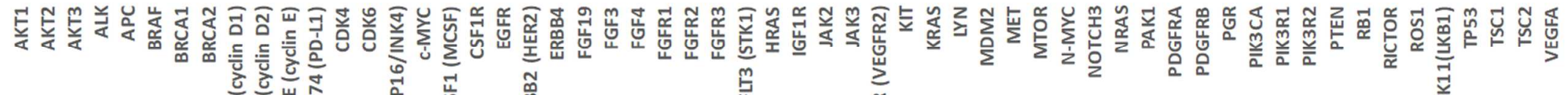



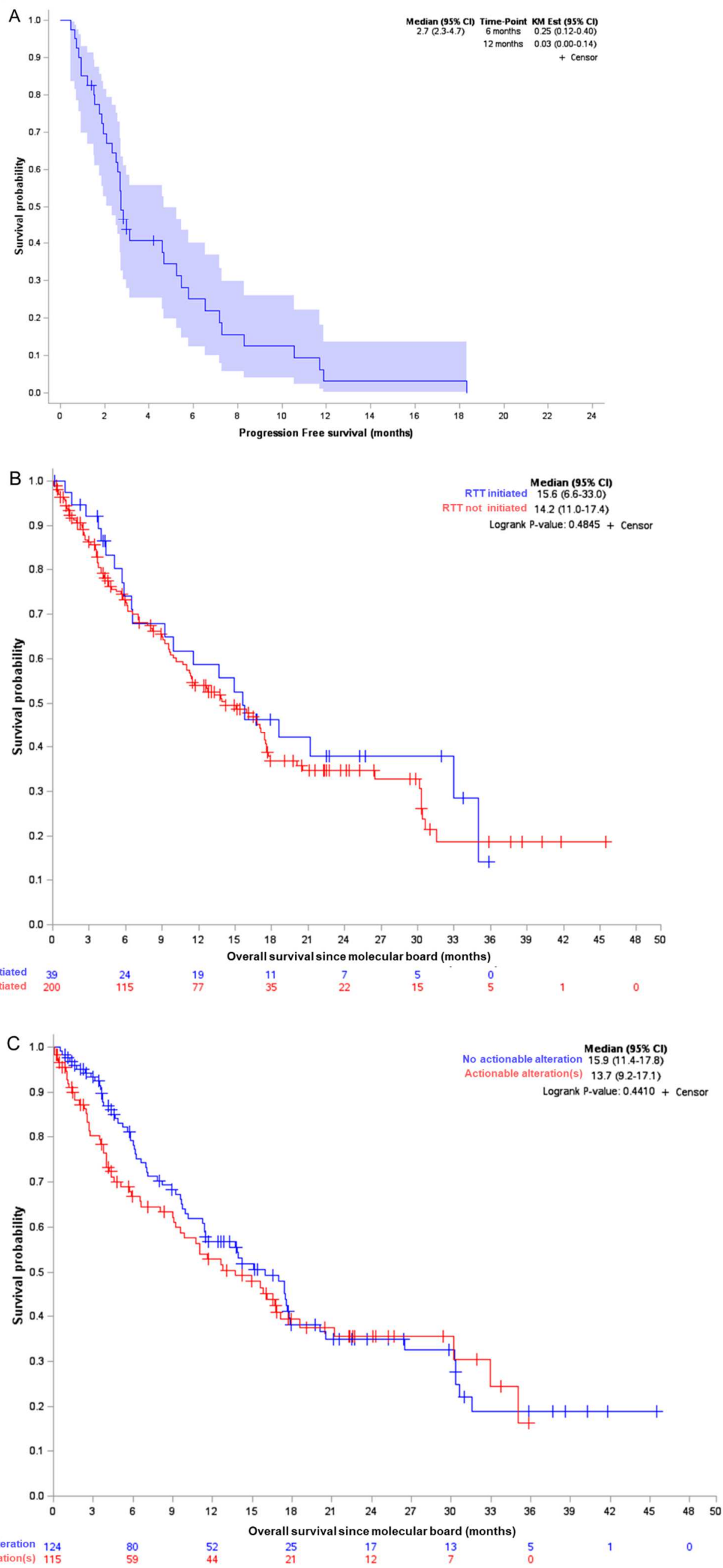


\begin{tabular}{|c|c|c|c|c|c|c|c|c|c|c|c|c|c|c|c|c|}
\hline & \multicolumn{14}{|c|}{ Localization } & \multirow{3}{*}{\multicolumn{2}{|c|}{$\begin{array}{c}\text { All analyzed } \\
\text { patients } \\
(n=279)\end{array}$}} \\
\hline & \multicolumn{4}{|c|}{ Ovarian cancer } & \multicolumn{4}{|c|}{ Uterine cancer } & \multicolumn{4}{|c|}{ Cervical cancer } & \multirow{2}{*}{\multicolumn{2}{|c|}{$\begin{array}{l}\text { Other } \\
(n=10)\end{array}$}} & & \\
\hline & \multicolumn{2}{|c|}{$\begin{array}{l}\text { Common } \\
(n=130)\end{array}$} & \multicolumn{2}{|c|}{$\begin{array}{c}\text { Rare } \\
(n=46)\end{array}$} & \multicolumn{2}{|c|}{$\begin{array}{c}\text { Common } \\
(n=13)\end{array}$} & \multicolumn{2}{|c|}{$\begin{array}{c}\text { Rare } \\
(n=48)\end{array}$} & \multicolumn{2}{|c|}{$\begin{array}{c}\text { Common } \\
(n=18)\end{array}$} & \multicolumn{2}{|c|}{$\begin{array}{c}\text { Rare } \\
(n=14)\end{array}$} & & & & \\
\hline \multicolumn{17}{|l|}{ Age at inclusion } \\
\hline Median (Min-Max) & \multicolumn{2}{|c|}{$61(21-81)$} & \multicolumn{2}{|c|}{$60(22-84)$} & \multicolumn{2}{|c|}{$63(35-75)$} & \multicolumn{2}{|c|}{$61(31-84)$} & \multicolumn{2}{|c|}{$45(31-71)$} & \multicolumn{2}{|c|}{$44(30-75)$} & \multicolumn{2}{|c|}{$58(38-74)$} & \multicolumn{2}{|c|}{$60(21-84)$} \\
\hline \multicolumn{17}{|l|}{ PS ECOG } \\
\hline 0 & 25 & $(21 \%)$ & 11 & $(27 \%)$ & 6 & $(46 \%)$ & 13 & $(31 \%)$ & 6 & $(35 \%)$ & 2 & $(14 \%)$ & 0 & $(0 \%)$ & 63 & $(25 \%)$ \\
\hline 1 & 85 & $(72 \%)$ & 28 & $(68 \%)$ & 7 & $(54 \%)$ & 23 & $(55 \%)$ & 9 & $(53 \%)$ & 11 & $(79 \%)$ & 8 & $(80 \%)$ & 171 & $(67 \%)$ \\
\hline 2 & 8 & $(7 \%)$ & 2 & $(5 \%)$ & 0 & $(0 \%)$ & 4 & $(10 \%)$ & 2 & $(12 \%)$ & 1 & $(7 \%)$ & 1 & $(10 \%)$ & 18 & $(7 \%)$ \\
\hline 3 & 0 & $(0 \%)$ & 0 & $(0 \%)$ & 0 & $(0 \%)$ & 2 & $(5 \%)$ & 0 & $(0 \%)$ & 0 & $(0 \%)$ & 1 & $(10 \%)$ & 3 & $(1 \%)$ \\
\hline 2 & 22 & $(18 \%)$ & 5 & $(17 \%)$ & 7 & $(54 \%)$ & 5 & $(12 \%)$ & 6 & $(43 \%)$ & 0 & $(0 \%)$ & 0 & $(0 \%)$ & 45 & $(19 \%)$ \\
\hline 3 & 73 & $(60 \%)$ & 23 & $(77 \%)$ & 4 & $(31 \%)$ & 32 & $(74 \%)$ & 5 & $(36 \%)$ & 5 & $(83 \%)$ & 8 & $(89 \%)$ & 150 & (64\%) \\
\hline FIGO stage at diagno & & & & & & & & & & & & & & & & \\
\hline Missing data & & 1 & & 0 & & 0 & & 2 & & 0 & & 1 & & 1 & 5 & 5 \\
\hline Stage I or II & 8 & $(6 \%)$ & 20 & $(44 \%)$ & 5 & $(39 \%)$ & 24 & $(52 \%)$ & 13 & $(72 \%)$ & 8 & $(62 \%)$ & 0 & $(0 \%)$ & 78 & (29\%) \\
\hline Stage III or IV & 121 & $(94 \%)$ & 26 & $(57 \%)$ & 8 & $(62 \%)$ & 22 & $(48 \%)$ & 5 & $(28 \%)$ & 5 & $(39 \%)$ & 9 & $(100 \%)$ & 196 & $(72 \%)$ \\
\hline Number of metastati & inclus & ion & & & & & & & & & & & & & & \\
\hline Missing data & & 0 & & 1 & & 0 & & 0 & & 0 & & 0 & & 0 & 1 & 1 \\
\hline 0 & 40 & $(31 \%)$ & 13 & $(29 \%)$ & 1 & $(8 \%)$ & 3 & $(6 \%)$ & 0 & $(0 \%)$ & 1 & $(7 \%)$ & 1 & $(10 \%)$ & 59 & (21\%) \\
\hline
\end{tabular}


Serous Adenocarcinoma

Endometrioid adenocarcinoma

$133(47.7 \%)$

$4(1.4 \%)$

Malignant mixed Mullerian tumor $\quad 9(3.2 \%)$

Mucinous adenocarcinoma $4(1.4 \%)$

Clear cell tumor $\quad 8(2.9 \%)$

Other $2(0.01 \%)$

Germ cell tumors

8 (2.9\%)

Sex cord stromal tumors

$7(2.5 \%)$

Sarcoma Leiomyosarcoma

$1(0.003 \%)$

Uterine Cancer

$n=61(21.9 \%)$

Epithelial carcinoma

$39(14.0 \%)$

Adenocarcinoma

$26(9.3 \%)$

Malignant mixed Mullerian tumor

$11(3.9 \%)$

Other

$2(0.01 \%)$

Sarcoma

22 (7.9\%)

Leiomyosarcoma

$13(4.7 \%)$

Stromal sarcoma

$8(2.9 \%)$

Other

$1(0.003 \%)$

Cervix cancer

$n=32(11.5 \%)$

Epithelial carcinoma

$29(10.4 \%)$

Adenocarcinoma

$11(4.0 \%)$

Squamous cell carcinoma

$18(6.5 \%)$

Other

$3(0.01 \%)$

Vulvar and Vaginal Cancer

$n=10(3.6 \%)$

Epithelial tumors

$6(2.2 \%)$

Adenocarcinoma

$5(0.02 \%)$

Squamous cell carcinoma

$1(0.003 \%)$

$3(0.01 \%)$

Sarcoma

$1(0.003 \%)$ 


\begin{tabular}{|c|c|c|c|c|c|c|c|c|c|c|c|c|c|c|c|c|}
\hline & \multicolumn{14}{|c|}{ Localization } & \multirow{3}{*}{\multicolumn{2}{|c|}{$\begin{array}{c}\text { All analyzed } \\
\text { patients } \\
(n=279)\end{array}$}} \\
\hline & \multicolumn{4}{|c|}{ Ovarian cancer } & \multicolumn{4}{|c|}{ Uterine cancer } & \multicolumn{4}{|c|}{ Cervical cancer } & \multirow{2}{*}{\multicolumn{2}{|c|}{$\begin{array}{l}\text { Other } \\
(n=10)\end{array}$}} & & \\
\hline & \multicolumn{2}{|c|}{$\begin{array}{l}\text { Common } \\
(n=130)\end{array}$} & \multicolumn{2}{|c|}{$\begin{array}{c}\text { Rare } \\
(n=46)\end{array}$} & \multicolumn{2}{|c|}{$\begin{array}{c}\text { Common } \\
(n=13)\end{array}$} & \multicolumn{2}{|c|}{$\begin{array}{c}\text { Rare } \\
(n=48)\end{array}$} & \multicolumn{2}{|c|}{$\begin{array}{c}\text { Common } \\
(n=18)\end{array}$} & \multicolumn{2}{|c|}{$\begin{array}{c}\text { Rare } \\
(n=14)\end{array}$} & & & & \\
\hline \multicolumn{17}{|c|}{ Length between inclusion and molecular board (months) } \\
\hline Median (Min-Max) & \multicolumn{2}{|c|}{$2.8(1-11)$} & \multicolumn{2}{|c|}{$2.8(1-8)$} & \multicolumn{2}{|c|}{$2.3(1-5)$} & \multicolumn{2}{|c|}{$2.7(0.4-9)$} & & $(2-6)$ & & $(1-8)$ & 3.2 & (2-6) & $2.9(0$. & $.4-11)$ \\
\hline Number of actionable alterations & & & & & & & & & & & & & & & & \\
\hline 0 & 73 & (56\%) & 26 & $(57 \%)$ & 5 & (39\%) & 24 & $(50 \%)$ & 8 & $(44 \%)$ & 6 & (43\%) & 6 & $(60 \%)$ & 148 & $(53 \%)$ \\
\hline 1 & 32 & (25\%) & 16 & (35\%) & 2 & $(15 \%)$ & 17 & (35\%) & 8 & $(44 \%)$ & 4 & (29\%) & 4 & $(40 \%)$ & 83 & $(30 \%)$ \\
\hline 2 & 18 & (14\%) & 3 & (7\%) & 5 & $(39 \%)$ & 2 & $(4 \%)$ & 2 & $(11 \%)$ & 3 & (21\%) & 0 & $(0 \%)$ & 33 & (12\%) \\
\hline 3 & 5 & $(4 \%)$ & 1 & $(2 \%)$ & 1 & $(8 \%)$ & 0 & $(0 \%)$ & 0 & $(0 \%)$ & 0 & $(0 \%)$ & 0 & $(0 \%)$ & 7 & $(3 \%)$ \\
\hline 4 & 0 & $(0 \%)$ & 0 & $(0 \%)$ & 0 & $(0 \%)$ & 3 & (6\%) & 0 & $(0 \%)$ & 1 & (7\%) & 0 & $(0 \%)$ & 4 & $(1 \%)$ \\
\hline 5 & 1 & (1\%) & 0 & $(0 \%)$ & 0 & $(0 \%)$ & 1 & $(2 \%)$ & 0 & $(0 \%)$ & 0 & $(0 \%)$ & 0 & $(0 \%)$ & 2 & $(1 \%)$ \\
\hline 6 & 1 & (1\%) & 0 & $(0 \%)$ & 0 & $(0 \%)$ & 1 & $(2 \%)$ & 0 & $(0 \%)$ & 0 & $(0 \%)$ & 0 & $(0 \%)$ & 2 & $(1 \%)$ \\
\hline Class of actionable alterations & & & & & & & & & & & & & & & & \\
\hline Mutation(s) & 33 & $(25 \%)$ & 14 & (30\%) & 8 & $(62 \%)$ & 10 & (21\%) & 5 & $(28 \%)$ & 5 & (36\%) & 1 & $(10 \%)$ & 77 & $(28 \%)$ \\
\hline Amplification(s) & 27 & (21\%) & 6 & $(13 \%)$ & 0 & $(0 \%)$ & 12 & (25\%) & 5 & $(28 \%)$ & 4 & (29\%) & 3 & $(30 \%)$ & 57 & $(20 \%)$ \\
\hline Deletion(s) & 9 & (7\%) & 3 & (7\%) & 0 & $(0 \%)$ & 7 & $(15 \%)$ & 0 & $(0 \%)$ & 3 & (21\%) & 0 & $(0 \%)$ & 22 & $(8 \%)$ \\
\hline Treatment recommendation & & & & & & & & & & & & & & & & \\
\hline Yes & 44 & $(34 \%)$ & 12 & $(26 \%)$ & 7 & $(54 \%)$ & 19 & $(40 \%)$ & 7 & $(39 \%)$ & 7 & $(50 \%)$ & 3 & (30\%) & 99 & $(36 \%)$ \\
\hline No & 86 & $(66 \%)$ & 34 & |(74\%) & 6 & $(46 \%)$ & 29 & $(60 \%)$ & 11 & $(61 \%)$ & 7 & $(50 \%)$ & 7 & $|(70 \%)|$ & 180 & (65\%) \\
\hline Number of recommended treatmen & & & & & & & & & & & & & & & & \\
\hline 0 & 86 & (66\%) & 34 & $(74 \%)$ & 6 & $(46 \%)$ & 29 & $(60 \%)$ & 11 & (61\%) & 7 & $(50 \%)$ & 7 & $(70 \%)$ & 180 & $(65 \%)$ \\
\hline 1 & 32 & $(25 \%)$ & 9 & $(20 \%)$ & 3 & $(23 \%)$ & 16 & (33\%) & 7 & (39\%) & 4 & (29\%) & 3 & (30\%) & 74 & (27\%) \\
\hline 2 & 9 & (7\%) & 3 & (7\%) & 4 & (31\%) & 2 & $(4 \%)$ & 0 & $(0 \%)$ & 3 & (21\%) & 0 & $(0 \%)$ & 21 & $(8 \%)$ \\
\hline 3 & 1 & $(1 \%)$ & 0 & $(0 \%)$ & 0 & $(0 \%)$ & 1 & $(2 \%)$ & 0 & $(0 \%)$ & 0 & $(0 \%)$ & 0 & $(0 \%)$ & 2 & $(1 \%)$ \\
\hline 4 & 2 & (2\%) & 0 & $(0 \%)$ & 0 & $(0 \%)$ & 0 & $(0 \%)$ & 0 & $(0 \%)$ & 0 & $(0 \%)$ & 0 & $(0 \%)$ & 2 & $(1 \%)$ \\
\hline Previous lines of systemic treatmen & & & & & & & & & & & & & & & & \\
\hline PI3K-AKT-mTOR inhibitor & 16 & (12\%) & 5 & $(11 \%)$ & 8 & $(62 \%)$ & 14 & (29\%) & 5 & (28\%) & 6 & $(43 \%)$ & 2 & $(20 \%)$ & 56 & (20\%) \\
\hline Sorafenib (multi target inhibitor) & 17 & $(13 \%)$ & 3 & $(7 \%)$ & 2 & $(15 \%)$ & 1 & $(2 \%)$ & 0 & $(0 \%)$ & 3 & $(21 \%)$ & 0 & $(0 \%)$ & 26 & $(9 \%)$ \\
\hline HER2 inhibitor & 3 & (2\%) & 1 & $(2 \%)$ & 0 & $(0 \%)$ & 3 & (6\%) & 0 & $(0 \%)$ & 1 & (7\%) & 1 & $(10 \%)$ & 9 & $(3 \%)$ \\
\hline FGF inhibitor & 3 & (2\%) & 0 & $(0 \%)$ & 2 & $(15 \%)$ & 0 & $(0 \%)$ & 2 & (11\%) & 0 & $(0 \%)$ & 0 & $(0 \%)$ & 7 & $(3 \%)$ \\
\hline BRAF inhibitor & 3 & (2\%) & 1 & $(2 \%)$ & 0 & $(0 \%)$ & 1 & (2\%) & 0 & $(0 \%)$ & 0 & $(0 \%)$ & 0 & $(0 \%)$ & 5 & $(2 \%)$ \\
\hline BET inhibitor & 2 & (2\%) & 1 & $(2 \%)$ & 0 & $(0 \%)$ & 2 & $(4 \%)$ & 0 & $(0 \%)$ & 0 & $(0 \%)$ & 0 & $(0 \%)$ & 5 & $(2 \%)$ \\
\hline CDK inhibitor & 4 & (3\%) & 1 & $(2 \%)$ & 0 & $(0 \%)$ & 0 & $(0 \%)$ & 0 & $(0 \%)$ & 0 & $(0 \%)$ & 0 & $(0 \%)$ & 5 & $(2 \%)$ \\
\hline MDM2 inhibitor & 0 & $(0 \%)$ & 0 & $(0 \%)$ & 0 & $(0 \%)$ & 5 & $(10 \%)$ & 0 & $(0 \%)$ & 0 & $(0 \%)$ & 0 & $(0 \%)$ & 5 & $(2 \%)$ \\
\hline ALK inhibitor & 3 & $(2 \%)$ & 1 & $(2 \%)$ & 0 & $(0 \%)$ & 0 & $(0 \%)$ & 0 & $(0 \%)$ & 0 & $(0 \%)$ & 0 & $(0 \%)$ & 4 & $(1 \%)$ \\
\hline MAP kinase inhibitor & 4 & (3\%) & 0 & $(0 \%)$ & 0 & $(0 \%)$ & 0 & (0\%) & 0 & $(0 \%)$ & 0 & $(0 \%)$ & 0 & $(0 \%)$ & 4 & $(1 \%)$ \\
\hline Bcr-Abl inhibitor & 1 & (1\%) & 1 & $(2 \%)$ & 0 & $(0 \%)$ & 0 & $(0 \%)$ & 1 & $(6 \%)$ & 0 & $(0 \%)$ & 0 & $(0 \%)$ & 3 & $(1 \%)$ \\
\hline Pazopanib (multi target inhibitor) & 0 & $(0 \%)$ & 2 & $(4 \%)$ & 0 & $(0 \%)$ & 0 & $(0 \%)$ & 0 & $(0 \%)$ & 1 & (7\%) & 0 & $(0 \%)$ & 3 & $(1 \%)$ \\
\hline PARP inhibitor & 1 & $(1 \%)$ & 0 & $(0 \%)$ & 0 & $(0 \%)$ & 1 & $(2 \%)$ & 0 & $(0 \%)$ & 0 & $(0 \%)$ & 0 & $(0 \%)$ & 2 & $(1 \%)$ \\
\hline RAK / MEK inhibitors & 1 & (1\%) & 0 & $(0 \%)$ & 0 & $(0 \%)$ & 0 & $(0 \%)$ & 0 & $(0 \%)$ & 0 & $(0 \%)$ & 0 & $(0 \%)$ & 1 & $(0 \%)$ \\
\hline JAK inhibitor & 0 & $(0 \%)$ & 1 & $(2 \%)$ & 0 & $(0 \%)$ & 0 & $(0 \%)$ & 0 & $(0 \%)$ & 0 & $(0 \%)$ & 0 & $(0 \%)$ & 1 & $(0 \%)$ \\
\hline RAF-MEK inhibitor & 1 & $(1 \%)$ & 0 & $(0 \%)$ & 0 & $(0 \%)$ & 0 & $(0 \%)$ & 0 & $(0 \%)$ & 0 & $(0 \%)$ & 0 & $(0 \%)$ & 1 & $(0 \%)$ \\
\hline NOCH inhibitor & 1 & $(1 \%)$ & 0 & $(0 \%)$ & 0 & $(0 \%)$ & 0 & $(0 \%)$ & 0 & $(0 \%)$ & 0 & $(0 \%)$ & 0 & $(0 \%)$ & 1 & $(0 \%)$ \\
\hline Endocrine therapy & 0 & $(0 \%)$ & 0 & $(0 \%)$ & 0 & $(0 \%)$ & 0 & $(0 \%)$ & 1 & $(6 \%)$ & 0 & (0\%) & 0 & $(0 \%)$ & 1 & $(0 \%)$ \\
\hline PDL1-PD1 inhibitor & 1 & (1\%) & 0 & $(0 \%)$ & 0 & $(0 \%)$ & 0 & $(0 \%)$ & 0 & $(0 \%)$ & 0 & $(0 \%)$ & 0 & $(0 \%)$ & 1 & $(0 \%)$ \\
\hline VEGF inhibitor & 1 & $(1 \%)$ & 0 & $(0 \%)$ & 0 & $(0 \%)$ & 0 & $(0 \%)$ & 0 & $(0 \%)$ & 0 & $(0 \%)$ & 0 & $(0 \%)$ & 1 & $(0 \%)$ \\
\hline
\end{tabular}

